\title{
Efficiency and safety of the rectus sheath block analgesia following midline laparotomy
}

\author{
Kinnunen $\mathrm{M}^{1}$, Purdy $\mathrm{M}^{2}$, Kokki Merja ${ }^{3}$, Anttila $\mathrm{M}^{4}$, Kokki $\mathrm{H}^{1}$ \\ 'School of Medicine, University of Eastern Finland, Kuopio, Finland \\ 2Department of Surgery, Kuopio University Hospital, Kuopio, Finland \\ ${ }^{3}$ Department of Anaesthesia and Operative Services, \\ Kuopio University Hospital, Kuopio, Finland \\ ${ }^{4}$ Department of Gynaecology, Department of Oncology, \\ Kuopio University Hospital, Kuopio, Finland
}

\section{Background and goal of study}

Postoperative pain is the most common complaint after surgery. Pain after midline laparotomy is derived from multiple origins; the abdominal wall, viscera, and from peritoneal irritation.

A single agent or pain-relieving technique is seldom sufficient for postoperative pain management. Opioid analgesics are especially effective for controlling nociceptive and visceral pain'. Peripheral abdominal wall blocks are increasingly used after laparotomy.

Central nervous blockades are highly effective but have contraindications. Increasing use of anticoagulant drugs may prevent use of them.

The rectus sheath block (RSB) has been investigated in laparotomy ${ }^{2}$, but there is a controversy about its efficiency ${ }^{3}$.

This study was designed to evaluate the efficiency and safety of RSB after laparotomy.

\section{Patients and methods}

56 patients undergoing midline laparotomy were randomized in four groups: control $(n=12)$, single bolus $(n=16)$, repeated boluses $(n=12)$ and continuous infusion ( $n=17)$ RSB analgesia groups. Consumption of oxycodone with iv PCA-pump for rescue analgesia were registered for the first48 postoperative hours. Pain scores and patient satisfaction were assessed by a numerical rating scale (0-10). Plasma concentrations of oxycodone and metabolites were analysed. All adverse events and complications during the hospital stay and 30 days after surgery were recorded.

\section{References}

1. Kokki H, Kokki M, Sjövall S. Oxycodone for the treatment of postoperative pain. Expert Opin Pharmacother 2012; 13: 1045-1058.

2. Tudor EC, Yang W, Brown R, Mackey PM. Rectus sheath catheters provide equivalent analgesia to epidurals following laparotomy for colorectal surgery. Ann R Coll Surg Eng 2015;97(7):530-3.

3. Kim JS, Choi JB, Lee SY, et al. Pain related to robotic cholecystectomy with lower abdominal ports: effect of the

bilateral ultrasound-guided split injection technique of rectus sheath block in female patients: A prospective randomised trial. Medicine (Baltimore) 2016 doi: 10.1097/MD.0000000000004445.

\section{Results}

Oxycodone consumption was less during the first $12 \mathrm{~h}$ in the repeated boluses and continuous infusion group $(p=0.07)$ but thereafter similar in the four groups. Plasma oxycodone concentrations were similar in all four groups, the mean analgesic concentration of oxycodone was 20$30 \mathrm{ng} / \mathrm{ml}$ (Table 1).

Pain at rest at $24 \mathrm{~h}$ was less in the repeated bolusesgroups $(p=0.006)$ and patient satisfaction better $(p=0.025)$ than that in the control-group.

No serious or unexpected adverse events were noted during hospital stay. During the first 30 postoperative days, two superficial wound infections (one in the singledose group, one in the infusion group) and one deep wound infection (in the control group) were noted.

Table. Cumulative oxycodone consumption (mg). Data are $95 \%$ confidence interval of means.

\begin{tabular}{|l|c|c|c|c|}
\hline & $\begin{array}{c}\text { Control } \\
\mathrm{n}=12\end{array}$ & $\begin{array}{c}\text { Single } \\
\text { bolus } \\
\mathrm{n}=16\end{array}$ & $\begin{array}{c}\text { Repeated } \\
\text { doses } \\
\mathrm{n}=12\end{array}$ & $\begin{array}{c}\text { Continuous } \\
\text { infusion }\end{array}$ \\
\hline $\begin{array}{l}\mathrm{n} \text { h after } \\
\text { surgery }\end{array}$ & $24-49$ & $29-61$ & $22-39$ & $16-26$ \\
\hline $\begin{array}{l}\text { 24 h after } \\
\text { surgery }\end{array}$ & $35-86$ & $50-98$ & $37-62$ & $33-54$ \\
\hline $\begin{array}{l}\text { 48 h after } \\
\text { surgery }\end{array}$ & $55-131$ & $78-167$ & $58-94$ & $55-96$ \\
\hline
\end{tabular}

\section{Conclusions}

Multimodal postoperative analgesia with RSB using repeated boluses or continuous infusion via catheters may enhanced analgesia in patients having midline laparotomy.
Kuopio

University Hospital 